"The submitted manuscrlet has been

authomed by a contractor of the U.S.

Government under contract No. DE.

AC05-84OR21400. Accordingly, the U.S.

Covernment retains a nonexclusive,

royalty-free license to publish or

reproduce the published form of this

contribution, or allow others to do so,

for U.S. Government purposes."

\title{
FORMATION OF ALUMINUM FILMS ON SILICON BY ION BEAM DEPOSITION: A COMPARISON WITH IONIZED CLUSTER BEAM DEPOSITION
}

CONF-900936--12

DE91 001276

R.A.Zuhr, T.E.Haynes, and M.D.Galloway, Oak Ridge National Laboratory,* Oak Ridge, TN

S.Tanaka, A.Yamada, and I.Yamada, Ion Beam Engineering Laboratory, Kyoto University, Sakyo, Kyoto 6C6, Japan

The direct ion beam deposition (IBD) technique has been used to study the formation of oriented aluminum films on single crystal silicon substrates. In the IBD process, thin film growth is accomplished by decelerating a magnetically-analyzed ion beam to low energies $(10-200 \mathrm{eV})$ for direct deposition onto the substrate under UHV conditions. The energy of the incident ions can be selected to provide the desired growth conditions, and the mass analysis ensures good team purity.

The aluminum on silicon system is one which has been stldied extensively by ionized cluster beam (ICB) deposition. This technique has produced intriguing results for aluminum, with oriented crystalline films being formed at room temperature in spite of the $25 \%$ mismatch in lattice constant between aluminum and silicon.[1]

In this work, we have studied the formation of such films by IBD, with emphasis on the effects of ion energy, substrate temperature, and surface cleanliness. Oriented films have

* Research sponsored by the Division of Materials Science, U.S. Department of Energy under contract DE-AC05-84OR21400 with Martin Marietta Energy Systems, Inc.
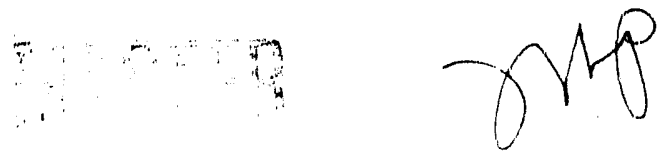


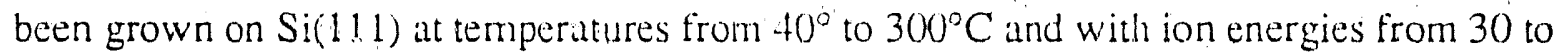
$120 \mathrm{eV}$ per ion. Completed films were analyzed by ion scattering, $\mathrm{x}$-ray diffraction, scanning electron microscopy, and optical microscopy. Results achieved for thin films grown by IBD are compared with results for similar films grow'n by ICB deposition.

\section{Introduction}

The formation of $\mathrm{Al}$ films on $\mathrm{Si}$ at low temperatures is of fundamental interest in thin film physics because of the unusual interface properties this system exhibits. It has been demonstrated that oriented crystalline Al films can be grown on $\mathrm{Si}(111)$ and $\mathrm{Si}(100)$ surfaces at room temperature by ionized cluster beam deposition (ICB), and by the related technique of partially ionized beam deposition, even though there is a large mismatch in the size of the respective lattices (25\%).[1-4] The films grow in an epitaxial orientation on the $\mathrm{Si}(111)$ surface, with all axes parallel to those of the substrate, while rotated regions of Al(110) grow on the $\mathrm{Si}(100)$ surface.(3) In addition, a special atomic relationship, in which the epitaxial Al layer is completely incommensuraie and unstrained, has been observed at the $\mathrm{Al} / \mathrm{Si}$ interface.[5] It is of interest to determine whether similar oriented growth can be achieved by other thin film deposition techniques.

The $\mathrm{Al}$ on Si systern is especially interesting, not only because of its fundamental properties, but also because $\mathrm{Al}$ is presently the conductor of choice for metallization in the processing of integrated circuits for microelectronics. Control of grain size and uniformity during this Al metallization is critical to the reliability of such conductors, particularly during thermal cycling. Ore possible way to achieve such control is through the introduction of energy in the form of energetic ions during film growth.[6]

For these reasons, a study of Al film formation on Si by the technique of direct ion beam deposition (IBD) was begun at Oak Ridge National Laboratory (ORNL). IBD has 
been used previously to study thin film growth in a number of areas including low temperature epitixy of semiconductors, low temperature formation of silicides, and the growth of isotopic heterostructures. [7-9]. In particular, epitaxial metal films have already been grown by IBD for lattice-mismatched systems such as Fe on Ag.[10] In this paper we will describe the formation of oriented Al films on single crystal Si substrates by direct deposition from a low-energy mass-analyzed ion beam.

\section{Experimental Procedure}

Thin Al films were grown on Si substrates by the direct ion beam deposition technique using the system developed at ORNL. This IBD system has been described previously[11] and consists of a modified Freeman ion source, an analyzing magnet, differential pumping chambers, and a deceleration lens assembly. The ions are extracted from the source at $3.5 \mathrm{keV}$ and magnetically mass analyzed to provide beams of a single isotope of a single element. The analyzed beam is then passed through a trap to eliminate neutrals, and through three stages of differential pumping to a UHV target chamber where it is decelerated to deposition energy immediately in front of the substrate by a four element electrostatic lens assembly. Deceleration near the target minimizes the probiems associated with transporting low energy ion beams. Ion current density is dependent on energy but is typically on the order of $5 \mathrm{uA} / \mathrm{cm}^{2}$ over the $3 \mathrm{~cm}^{2}$ deposition area for energies in the range from 30 to $120 \mathrm{eV}$. The chamber was baked before deposition to give a base pressure of $2 \times 10^{-10} \mathrm{~T}$ and pressures during deposition of $1-2 \times 10^{-9} \mathrm{~T}$.

Substrates were cut from semiconductor grade single crystal $\mathrm{n}$ - Si and chemically cleaned immediately prior to introduction into the vacuum system. The cleaning procedure was the same one used by Yamada et al for ICB deposited samples.[12] The principal steps were cleaning in organic solvents, oxide stripping in HF, and growth of a new 
protective oxide by wet chemistry. After insertion into the vacuum system, the samples were outgassed ut temperatures up to $600^{\circ} \mathrm{C}$. The final removal of the protective oxide was done in situ just before the deposition by reactive ion beam cleaning using $\mathrm{O}$ and $\mathrm{Cl}$ ions at $500^{\circ} \mathrm{C}$. Temperatures were monitoded during the cieaning procedure with an infrared pyrometer, and surface cleanliness was checked by in situ Auger spectroscopy before deposition.

In order to achieve the room termperature conditions that are typical for ICB of $\mathrm{Al}$ on $\mathrm{Si}$, the samples had to be actively cooled after the high temperature cleaning procedure. Because of the high potentials at which the deceleration lens operates $(35 \mathrm{keV})$, direct incorporation of cooling linzs was not practical. Instead, a liquid nitrogen cooled sold finger which could be brought into contacr with the sample holder was constructed. With this cold finger the sample could be cooled from an annealing temperature of $650^{\circ} \mathrm{C}$ to below $40^{\circ} \mathrm{C}$ in one hour.

The completed films were studied by $1.5 \mathrm{MeV}$ He ion backscattering, scanning electron microscopy, optical microscopy, and $x$-ray diffraction using standard analysis techniques.

\section{Results and Discission}

The quality of Al films formed on cleaned $\mathrm{Si}(111)$ substrates has been investigated as a function of ion energy, substrate temperature, and surface cleanliness. Initial investigations showed that cleanliness of the substrate and contamination from background gasses had a significant effect on film growth. Even in the low 10-9 $\mathrm{T}$ range where the

ORNL depositon chamber operates during active beam deposition, bombardment by residual gasses, primarily water and hydrogen, can result in film contamination on the $1 \%$ level, which is sufficient to alter the growth properties. Cloudy films resulted from 
growth under these conditions. Improvements in the in situ sample cleaning procedure and baking of the chamber prior to each deposition were necessary to achieve the formation of shiny oriented Al films. After baking, the total pressure during deposition decreased less than a factor of two, but the decrease in water partial pressure was enough to eliminate measurable effects from oxygen contamination of the films. Substrate surface contamination was reduced to less than $1 \%$ of $\mathrm{C}$ and $\mathrm{O}$ as measured by Auger spectroscopy using a reactive ion cleaning technique with low energy $\mathrm{O}+$ and $\mathrm{Cl}+$ beams at moderate temperature, $500^{\circ} \mathrm{C}$.

Scanning electron micrographs of three Al(111) films grown on ion beam cleaned Si(111) under conditions of improved cleanliness are shown in Fig. 1. The films were grown with an ion energy of $120 \mathrm{eV}$ at temperatures of $300^{\circ} \mathrm{C}$ (top), $150^{\circ} \mathrm{C}$ (center), and $30^{\circ} \mathrm{C}$ (bottom). The effects of elevated temperature are clear, with the morphology of the surface being rougher for the high temperature depositions. At $300^{\circ} \mathrm{C}$, a collection of micron size islands separated by a network of deep canyons was formed. At $150^{\circ} \mathrm{C}$, the islands were broader, coalescing into a relatively smooth surface, with a network of depressions where the deep canyons had been observed at $300^{\circ} \mathrm{C}$. At room temperature, the surface was smooth and featureless to the limit of resolution of the SEM. This can be understood in terms of the surface properties of $\mathrm{Al}$ on $\mathrm{Si}$. The interface energy of $\mathrm{Al} / \mathrm{Si}$ is quite large due to the large lattice mismatch. This provides a thermodynamic driving force for three-dimensional Al cluster formation. Furthermore, the activation energy for surface diffusion of $\mathrm{Al}$ on $\mathrm{Si}$ is very low (0.3 to $0.6 \mathrm{eV}$ depending on surface orientation), so that migration occurs at moderate temperature. As the substrate temperature increases from room temperature to $300^{\circ} \mathrm{C}$, the surface mobility also increases, enhancing the formation of surface clusters and resulting in the more coursely textured surfaces observed in the micrographs.

The degree of crystallinity and orientation in these films can be determined from the 1.5 MeV He ion channeling spectra in Fig. 2. Interestingly, the minimum yield in the $\mathrm{Al}$ 
film, which is a direct measure of crystal cuality and orientation, improved from 0.80 at room temperature to $0.40^{\circ}$ at $150^{\circ} \mathrm{C}$, and to $\left(0.35^{\circ}\right.$ at $300^{\circ} \mathrm{C}$. This would be expected if the primary driving force for crystal formation were thermal. X-ray scattering analysis confirmed this improvement in crystal quality with temperature, indicating that the amount of twinning decreased from $25 \%$ in the $150 \mathrm{C}$ sample to $10 \%$ in the $300 \mathrm{C}$ sample. Thus, increased deposition temperature resulted in better crystalline quality, but rougher surface morphology in these ion beam deposited Al films.

In Fig. 3, ion channeling spectra are compared for IBD and ICB films deposited at room temperature. The IBD film was deposited at $30 \mathrm{eV}$, while the ICB film was made with a $5 \mathrm{kV}$ bias voltage.|13] It can be seen that the minimum yield for the IBD sample, 0.28 , is comparable to that of the ICB sample, although it is not as low as the best minimum yields (22\% on $\mathrm{Si}(111)$ and $15 \%$ on $\mathrm{Si}(100)$ ) reported for ICB deposited $\mathrm{Al}$ films.[14] This difference could be due to the higher average incident energy used in the IBD films, or to the lower deposition rate for the IBD samples that results in increased background impurity incorporation. Either of these effects could lead to greater defect concentrations in the IBD Al crystals. By contrast with films grown by either IBD or ICB, aluminum films prepared in a conventional evaporator show no channeling or orientation. The minimum yield of this $30 \mathrm{eV}$ IBD film (28\%) is considerably better than that of the $120 \mathrm{eV}$ room temperature film (80\%) shown in Fig. 2, indicating that crystal quality improves with decreasing ion energy in this range. The average energy per incident particle for $\mathrm{IBD}$, even at $30 \mathrm{eV}$, is still higher than the average energy per atom for the ICB sample (on the order of $5 \mathrm{eV}$ ), so that further improvernent may be expected for IBD at lower energies. The surfaces of both of these samples were smooth and featureless under examination by optical microscopy. 


\section{Conclusions}

Crystalline Al(111) films that alre oriented with respect to the substrate have been grown on cleaned $\mathrm{Si}(111)$ surfaces by the direct ion beam deposition technique in spite of the large mismatch $(25 \%)$ in the lattice constants of these $t$ wo elements. X-ray diffraction and ion channeling studies show that the orientation of the $\mathrm{Al}(111)$ films is identical to that of the underlying $\mathrm{Si}$ for this crystil face, although some twinning is observed, especially at lower temperatures. Studies of Al film formation on Si(111) as a function of temperature from $30^{\circ}$ to $300^{\circ} \mathrm{C}$ show a strong increase in surface roughness with increasing temperature, which is ascribed to three-dimensional island-type growth resulting from the increased surface mobility of $\mathrm{Al}$ on $\mathrm{Si}$ at higher temperatures. Crystalline quality of the Al layers was found to improve with increasing temperature by both ion channeling and $x$-ray diffraction studies, indicating that thermal processes are important to crystal growth in this temperature regime. For roon temperature depositions, crystal quality on the (111) surface was also found to improve with decreasing ion energy, indicating that energies on the order of 100$) \mathrm{eV}$ may be introducing additional damage into the films. Similar effects have been observed in this energy range for the formation of epitaxial semiconductor films by the IBD process. [15]

Comparisons with Al films grown on $\mathrm{Si}(111)$ by the ICB process indicaie that the IBD Al films are comparable to those grown by cluster beams. Even though crystal quality is marginally less than that of the best ICB films, this ion beam work clearly demonstrates that cluster deposition is not a prerequisite for the formation of oriented Al films on Si(111) substrites.

\section{References}

1. I.Yamada, H.Inokawa, and T.Takagi, J. Appl. Plyss. 56, 2746 (1984). 
2. I. Yamada and T. Takagi, "Metallization by Ionized Cluster Beams," IEEE Transactions on Electron Devices, ED-34, No. 5, 1018 (1987).

3. I. Yamada, Appl. Surf. Sci. 43, 23 (1989).

4. C. H. Choi, R. A. Harper, A. S. Yapsir, and T. M. Lu, Appl. Phys. Lett. 51, 1992 (1987).

5. T. M. Lu, P. Rai, A. S. Yapsir, P. H. Chang, and T. J. Shaffner, Phys. Rev. B 39 9584 (1989).

6. G. K. Wolf and W. Ensinger, "Ion Bombardment and its Influence on Mechanical and Chemical Surface Properties," this conference, 1990.

7. E. R. Appleton, S. J. Pennycook, R. A. Zuhr, N. Herbots, and T. S. Noggle, "LowTemperature Epitaxial Growth of Si and Ge and Fabrication of Isotopic Heterostructures by Direci Ion Beam Deposition (IBD)," p. 975 in Beam Interactions with Materials and Atoms, ed. by H. H. Andersen and S. T. Picraux, North-Holland, Amsterdam, 1987; Nuct. Instrum. and Methods Phys. Res' Sect. B 19/20, 975 (1987).

8. T. E. Haynes, R. A. Zuhr, S. J. Pennycook, and B. R. Appleton, Appl. Phys. Lett. 54, 1439 (1989).

9. R. A. Zuhr, S. J. Penilycook, T. E. Haynes, and O. W. Holland, "Metal Silicides Formed by Direct Ion Beam Deposition," p. 47 in Processing and Characterization of 
Materials Using lon Beams, Vol. 128, ed. by Lynn E. Rehn, Joe E. Greene, and Fred A. Smidt, Materials Research Society, Pittsburgh Pennsylvania, 1989.

10. B. R. Appleton, I. S. Noggle, and R. A. Zuhr, unpublished results (1986).

11. R. A. Zuhr, B. R. Appleton, N. Herbots, B. C. Larson, T. S. Noggle, and S. J. Pennycook, J. Vac. Sci. and Technol. A 5, 2135 (1987).

12. S. Tanaka, Kyoto University, Kyoto 6(16, Japan, private communication.

13. ICB Al on Si(111) sample provided by S. Tanaka and I. Yamada, Kyoto University, Kyoto 606, Japan.

14. I. Yamada, H. Inokawa, K. Fukishima, and T. Takagi, Nucl. Inst. Meth. B 7/8 900 (1985).

15. R. A. Zuhr, G. D. Alton, B. R. Appleton, N. Herbots, T. S. Noggle, and S. J. Pennycook, "Direct Formation of Thin Films and Epitaxial Overlayers at Low Temperatures Using a Low-Energy (10-50) eV) Ion Beam Deposition System," p.243 in Materials Modification and Growth Using Ion Beams, ed. by U. Gibson, P. P. Pronko, and A. E. White, Materials Research Society, Pittsburgh, Pennsylvit..., 1987.

\section{DISCLAIMER}

\footnotetext{
This report was prepared as an account of work sponsored by an agency of the United States Government. Neither the United States Government nor any agency thereuf, nor any of their employees, makes any warranty, express or implied, or assumes any legal liability or responsibility for the accuracy, completeness, or usefulness of any information, apparatus. product, or process disclosed, or represents that its use would not infringe privately owned rights. Reference herein to any specific commercial product, process, or service by trade, name, trademark, manufacturer, or otherwise does not necessarily constitute or imply its endorsement, recommendation, or favoring by the United States Governruent or any agency thereof. The views and opinions of authors expressed herein do not necessarily state or reflect thase of the United Stites Governmint or any agency thereof.
} 


\section{FIGURE CAPTIONS}

Fig. 1 Scanning electron micrographs of oriented Al films formed on Si(111) by IBD at $120 \mathrm{eV}$ illustrate the changes in surface morphology that occur as a function of temperature. The surface changes from smooth at $30 \mathrm{C}$ (bottom), through an intermediate stage at $150 \mathrm{C}$ (center), to rough and islanded at $300 \mathrm{C}$ (top).

Fig, 2 Aligned $<111>(\mathrm{O})$ and random (ㅁ) $1.5 \mathrm{MeV}$ He ion scattering spectra for $120 \mathrm{eV}$ IBD Al films deposited on $\mathrm{Si}(111)$ at substrate temperatures of $30^{\circ} \mathrm{C}$ (bottom), $150^{\circ} \mathrm{C}$ (center), and $300^{\circ} \mathrm{C}$ (top). The channeling minimum yield, Xmin, decreases with increasing temperature, indicating improvement in crystal alignment of the films with temperature.

Fig. 3 Aligned $\langle 111\rangle$ (solid) and random (open) ion scattering spectra are compared for Al films deposited on $\mathrm{Si}(111)$ at room temperature by IBD at $30 \mathrm{eV}(O)$ and ICB at $5 \mathrm{kV}$ bias ( $(\mathbf{a})$. 

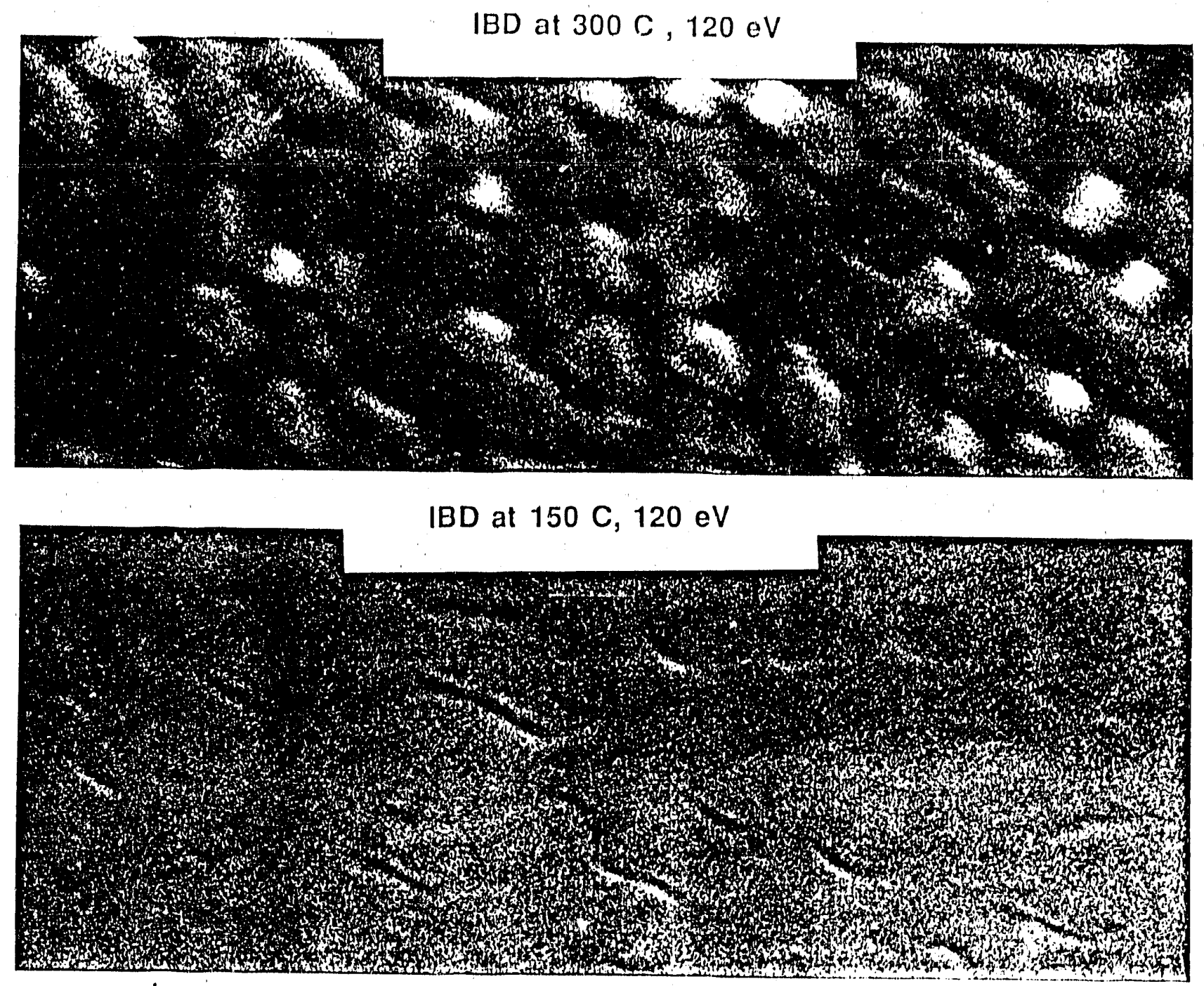

IBD at $30 \mathrm{C}, 120 \mathrm{eV}$
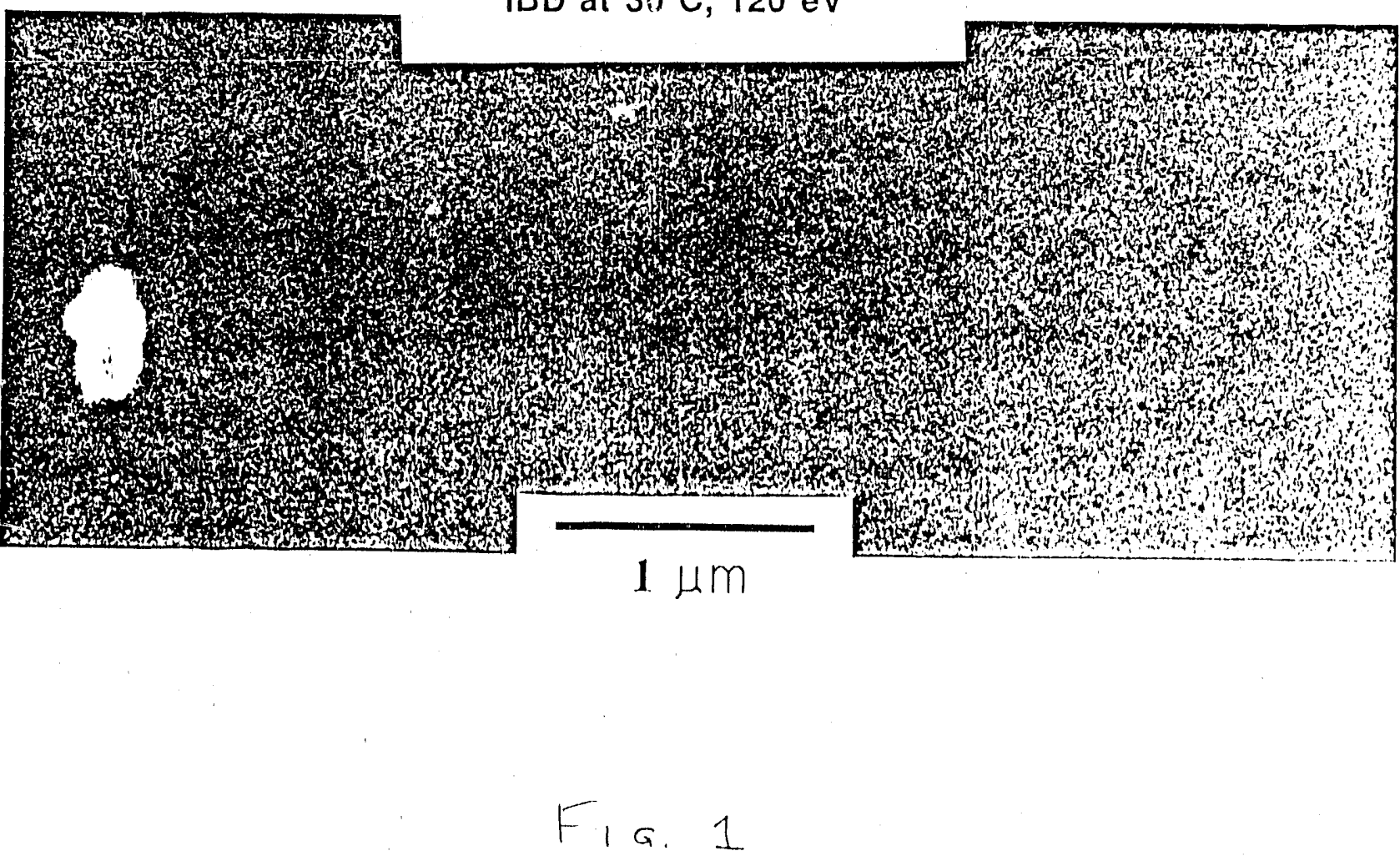


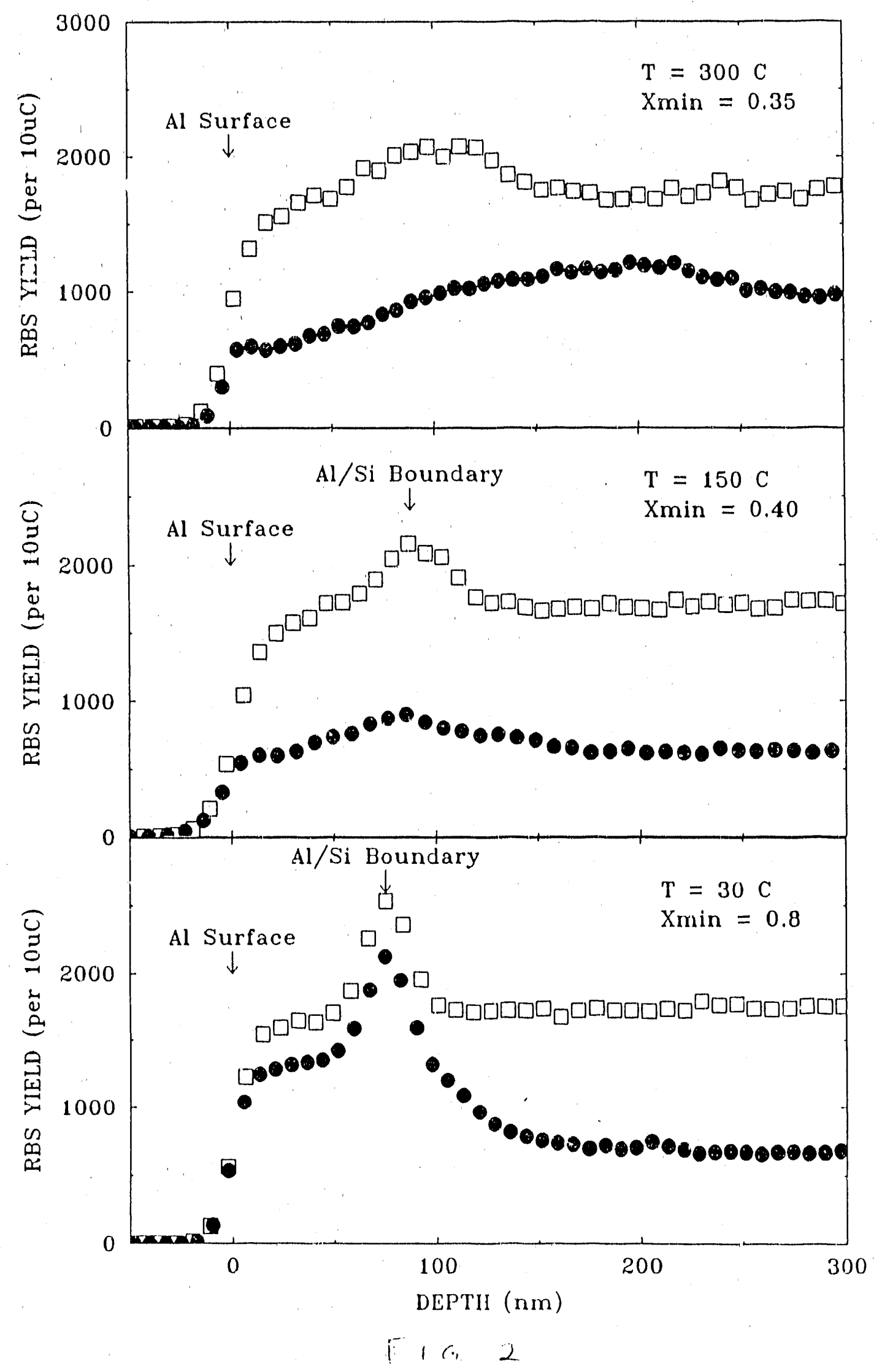




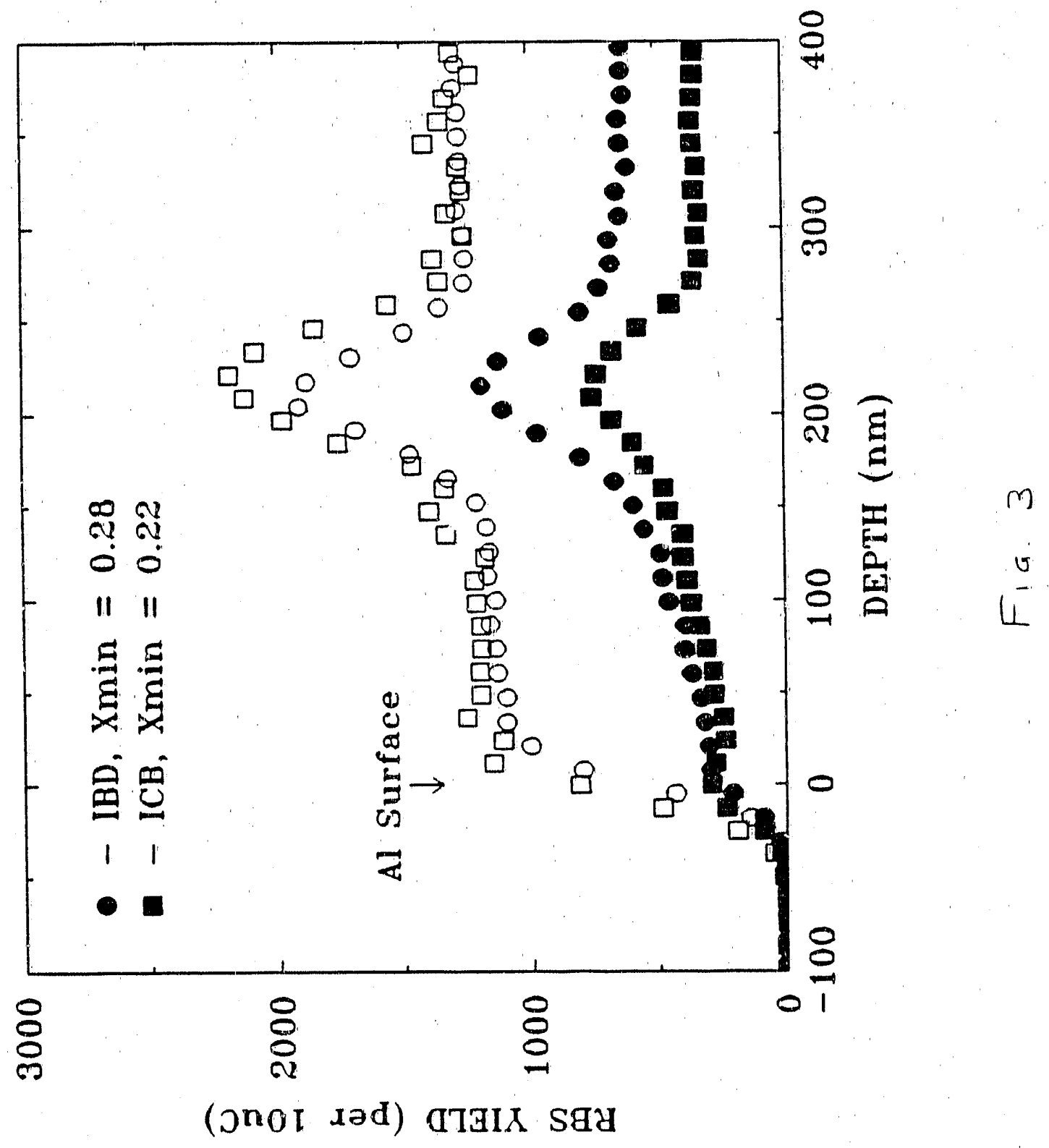



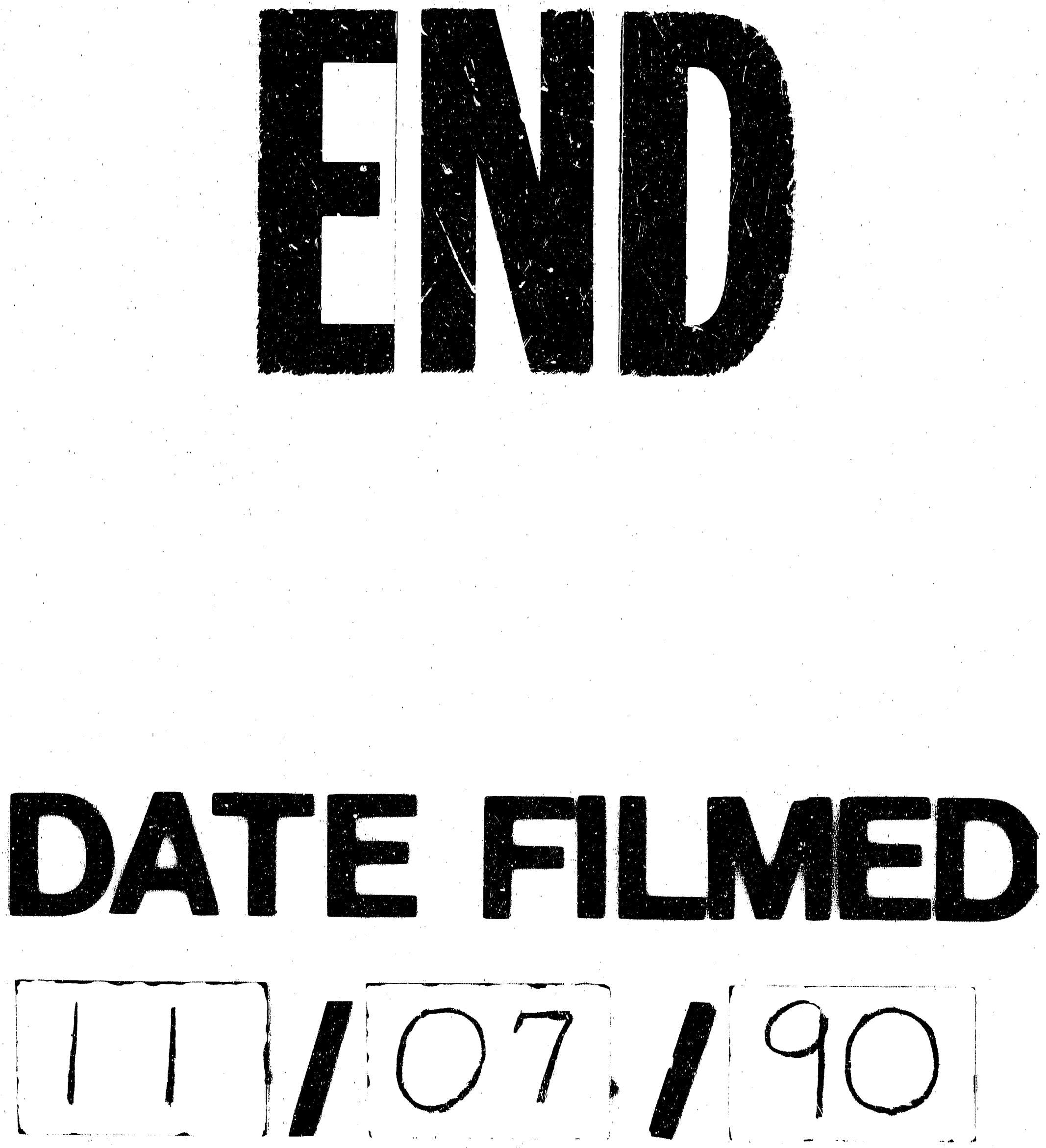
